LARISSA LÖßER, M.Sc.

E-mail: larissa.loesser@hs-merseburg.de

University of Applied Science Merseburg

Eberhard-Leibnitz-Straße 2, 06217 Merseburg, Germany
Transport and Sustainable Development

Review

Submitted: 30 June 2021

Accepted: 20 Oct. 2021

\title{
A PROCEDURE MODEL FOR LOW EMISSION TRANSPORTATION CHAIN PLANNING
}

\begin{abstract}
Low-emission planning in freight transportation is one of the main levers to reduce greenhouse gas emissions. For a sustainable planning approach, a strategic solution for this planning problem is needed. Based on several literature reviews, a procedure model is developed, which is meant to be used for the development and adjustment of a low-emission transportation chain reference model. The procedure model consists of the decision steps needed to develop a low-emission transportation chain (LETC) reference model and it is structured into main decision processes and sub-decision processes. A first draft of the LETC-Model is presented in form of an ARIS-Express model.
\end{abstract}

\section{KEYWORDS}

low emission, freight transportation, procedure model, reference model.

\section{INTRODUCTION}

A broad consensus among scientists exists about the anthropogenic cause of climate change. Three documents containing 'global warning to humanity' were published by some prominent scientists in the years 2000 [1], 2017 [2] and 2020 [3]. These papers were signed by 28,064 scientists from around the world to press the urgency of reacting to the global climate change [1-3]. In the year 2015, the Paris (climate) agreement was signed by 196 countries committing themselves to limit the global warming to 1.5 degrees above the level of 1990 [4]. The Federal Environmental Agency in Germany states that the measures will not be sufficient to reach the emission goals, this also applies to many other countries [5].

This is a big problem considering that most companies will not do more to limit their emission then they are required to by the government. A good example of this is the research on Sustainable Reporting by Stubbs et al. [6]. They state that no sustainable reporting is made due to factors such as the lack of external stakeholder pressure or the mindset that sustainable reporting is something "nice-to-do" and not a "must-do"; this statement is supported by Massaroni et al. [7]. Incidentally, the statement about the missing stakeholder pressure underlines that the current style of strategic decision-making in companies is not an emission-oriented one. It is based on integrated management concepts and reference models. The interpretation of the relationship of companies to their environments in these models is decisive for their actions on a strategic, tactical, and operational level.

The following two examples are used to illustrate if and how the natural environment is included in the strategic planning processes of companies. One should start with the St. Gallen Management model of Rüegg-Stürm [8] which 'has already influenced generations of managers' [9]. In the model, the overall framework is set by society considerations and not by consideration of natural resources and limitations. Rüegg-Stürm [8] describes and advises a shift from Normativism - the consideration of all interests, norms and values in a society-to Relativism - the consideration of "requests and interests" and "norms and values" of stakeholders which are useful to improve companies' market position. It means the emission-reduction will only be pursued if demanded by the "important" stakeholders.

Rieder and Lawson [9] have developed one of the most recent models called the AMPLE-Model. They depict the natural environment as the outer layer of their model, but natural environment considerations are only made within three corporate concepts (performance-based, financial, and social). Rieder and Lawson [9] explain this by saying: 'There is no business concept related to the natural environment as a company can only react to environmental aspects at the technological, financial or social level (...)'. 
A proactive approach is important to secure the long-term survival of companies. What is needed is a change of mindset and a proper handling of the natural environment. This could be achieved by changing the strategic models that the decisions are based on. Not only is transportation the only economic sector in which emissions are expected to increase [10], but with $60 \%$ until 2050 the increase is expected to be very high [11]. To really change the transportation planning process in a long-term setting, a standardised planning is needed for the decision makers, especially considering that: 'Usually decision-makers have little or no knowledge of the modes they do not regularly use, (...)' [12].

Different definitions of reference models exist which also name different properties. In Table 1 properties are listed. The abbreviation RM will be used for reference model.

Many properties are mentioned only once and some of the authors identify properties that contradict each other. For example, Dold [13] describes RM's as a tool for a specific company/organisation or even a specific department while Becker et al.
[14] say that RMs do not have any specific scope.

Hars [23] claims that an RM should be so specific that it could be used on its own; on the other hand, Fettke and Loos [16] and Thomas [17] state that an RM always needs to be adapted to the user needs before it can be used. Thus, a universal definition does not seem to exist of an RM. This article is oriented to the basic approvals: a reference model is a conceptual approach; it has to serve as a blueprint for the development of more specific models; and it should be a process model.

For the development of a reference model, different approaches can be used. In regard to the scientific development of a reference model, a systematic and conceptual approach in the form of a procedure model is developed. Chapter 2 describes the literature reviews on which the procedure model and the developed framework for the low-emission transportation chain reference model (LETC-RM) are built. In this context, the term "Green models" includes models that are declared to be green or sustainable or are given an environmental or ecological orientation by their developers. The results in

Table 1 - Literature analysis: Reference models: transportation, green, LSP (author-provided)

\begin{tabular}{||c|c||}
\hline Properties & Author \\
\hline \hline Process orientation of RM & {$[13],[14],[15],[16],[17],[18],[19],[20],[21]$,} \\
\hline Conceptual approach & {$[13],[16],[17],[19],[22]$} \\
\hline Blueprint (basis for development of specific models) & {$[14],[15],[16],[17],[19],[20],[21],[23],[24]$} \\
\hline Claim to universality / generic solution & {$[13],[19],[21],[22]$} \\
\hline Leads to cost reduction & {$[17],[19],[20],[21]$} \\
\hline
\end{tabular}



Figure 1 - Systematic literature reviews 
the form of procedure model and RM framework development are presented and discussed in chapter 3. In chapter 4 , the next concluding steps that need to be taken to finalise the LETC-RM are discussed.

\section{METHODOLOGY}

The procedure model created in this article is a method for the development of a low-emission transportation chain reference model (LETC-RM). The procedure model is developed and filled with context borrowed from several systematic literature reviews. Figure 1 shows the three chosen review processes. For the three reviews, Science Direct, Scopus, EBESCOhost, and Researchgate are used as research databases. Figure 1 also shows the research aim, the number of reviewed books, papers and reports, and to what extent they are included in this article. Additionally, it shows the main area where the selected literature has been used.

The first literature review focuses on basic literature concerned with the development of reference models in general and is used to define the main and sub-steps of the procedure model. Eight reviewed articles and books are chosen out of 20 to define the steps of the process "Scope Definition" (Figure 2). In the second literature review, existing reference models for the specific area of low-emission transportation chains are used as the basis for orientation. The main searching phrases include: "Reference Model(s)", AND ("Logistics Service Providers" OR (("Emission calculation" OR "Emission reduction") OR ("Protection of" nature OR environment) OR Sustainability) OR ("Transportation planning") OR (Holistic AND ("Transportation Chains" OR "Supply Chains"))). Overall, 63 books, papers, and reports are reviewed. Based on the restrictions that are set, only nine models are chosen as the basis for the state-of-the-art step (2.1) in Figure 2. They are analysed in Table 2. Some additional articles are included for further information on the identified categories. Additionally, a third review is made to fill the further steps in Figure 2 with the much-needed information about low-emission transportation planning. For the literature search, several phrases are used in various combinations such as ("Logistics Service Provider" OR "Freight Forwarder" OR "3PL") AND ("Reference Model" OR "Transport Chain" OR "Transport Process" OR (Modality AND "freight transport")). More than 730 books, papers, and reports were found, 290 were reviewed, but only nine were chosen for this article.

\section{RESULTS AND DISCUSSION}

In the main section of this article, the results are presented in the form of procedure model and LETC-RM-Framework. As the Framework is built on the procedure model, the discussion is also made in this section.

\subsection{Decision steps in the procedure model}

In the first literature review, the basics of reference modelling were researched. Several articles and books were identified as they proposed or used different methods and steps for the development of a reference model. Based on the work of $[14,15,20$, 21, 24-26], a procedure model for the development of the LETC-RM was set up and it was mostly oriented to the steps taken by Becker et al. [14] and by Tzouvaras and Hess [25]. In this article, procedure model is a literal translation of the German technical term "Vorgehensmodell". As the term is not so common in English literature and can also be translated as "process model", the literal meaning has been retained in the work to differentiate it from process and object models used here in different contexts. Schedlbauer [27] defines and distinguishes between three models:

- Procedure models show target-oriented and systematic courses of action to reach a To-Be state from an As-Is state.

- Process models describe an expected reaction of a system to a certain event.

- Object models can be understood as virtual image of reality.

Figure 2 depicts the main and the sub-processes of the deduced procedure model. The overall development process is segmented into five steps.

\subsection{Main and sub-decision steps}

The different sub-steps are defined gradually by filling the main steps with information from the literature analyses 1, 2, and 3 (Figure 1). In the following, the steps $1.1-3.1$ in the procedure model are defined and executed.

\section{Problem definition}

The phase of problem definition consists of several steps that are used to specify the overall topic and theme of the model to be developed. The first sub-step of the domain definition is used to focus the reference model development on a certain area. This can include the specification of a certain structure, 




Figure 2 - Procedure model for the LETC-Reference model

behaviour, or function in a company, such as supply, production, or distribution [15], the distinction of a target market $[16,20]$, or concentration on a specific problem in an area [23]. The focus of the To-Be developed LETC-RM is defined by the identification of and concentration on the specific problem in the area of multi-modal freight transportation in combination with emission reduction efforts.

A reference model needs an overall aim to function as blueprint [16]. This aim is also the top-level target of the subsequent specified processes. The need for a low-emission transportation planning reference model was accounted for in Lößer and Sackmann and Lößer [28, 29] by the identification of required model properties for low-emission transportation planning and the discovery, of what strategic and standardised models for low-emission transportation chain planning were missing.

A very important step is the determination of a target user for the model. A vast number of actors are included in multi-mode transportation chains [30] but a specific form of agent plays a vital role. Transportation and other logistic services in multi-modal transportation chains are often outsourced to logistic service providers (LSPs). Lun et al. [31] state: 'Generally, shippers are seldom interested in which transport mode is used (e.g. road or/and rail), and the LSPs normally decide on the modes'. LSPs provide logistic services for customers, which can include all of their logistic functions [32]. They are often put on a level with 3PLs (Third Party Logistics) [33]. Therefore LSP/3PLs are defined as target users.

The main properties which should be integrated into the To-Be developed model to reach the overall aim need to be identified. The name has already been set as LETC-RM. Furthermore, properties identified by Lößer and Sackmann [28] are included in the model. In order to reach the aim of low-emission, low-emission planning must be given top priority, which calls for the development of key performance indicators (KPIs) for emission. It should be a standardised tool with respect to the emission unit and emission calculation methods, which can be used cooperatively. A certain flexibility is needed in it due to the complexity of the planning area and possible changes in emission policies.

\section{Scope definition}

Scope definition is a specification procedure of attributes for the model. It is distinguished from the domain definition (step 1.1) by the difference in the abstraction level. The scope definition is also oriented to the requirement analysis phase in Matook 
and Indulska [20]. As a basis for the scope definition, existing RMs are used for orientation. Thus, an extensive literature review was made (Review 2 in Figure 1) to determine the state-of-the-art step (2.1) and at the same time identify the modelling decisions required to be made. The models included in this literature review are searched in accordance with the perimeters set in the problem definition phase. The models are categorised by using a combination of the reference model catalogue of Fettke and Loos [24] and the model overview of Rixe and Augustin [34] as orientation for Table 2. The LETC-Reference Model is also included in the table to show the categorisation based on the obtained models and the differences.

The models are analysed for three basic requirements based on the problem definition phase. These requirements dictate that a model needs to be:

- an emission-oriented model,

- focused on transportation planning, and

- a logistics service provider as the intended user.

The first three categories in Table 2 are used to present the model as state of the art. The name of the model already gives a hint if it is a green model; and the domain specifies if the model is used in a transportation or logistical context. The third category, the intended user, shows if the model is meant to be used by an LSP.

Four models which can be summarised under the generic term of "green models" have been found; they are listed in columns 2-5 in Table 2. Most of them are based on the Supply Chain Reference (SCOR) Model. The SCOR Model is a standardised cross-industry planning model for supply chain activities, which was developed by the Supply Chain Council in 1996 and has been updated since [35]. The model looks at planning decisions based on processes connected to the manufacturing of products by defining them on different process levels. The overall strategic goals are defined as performance metrics on the top level.

The highly complex model includes a special application for sustainability which is part of Table 2 and is called "Sustainable SCOR". The global standards for sustainability reporting (GRI Standards) are used as a basis. The Sustainable SCOR is a framework for environmental accounting in the supply chain, based on a set of environmental metrics that can be added to the standard SCOR model. In Ala-Harja and Helo [36], the SCOR Model is used to test three scenarios for emission reduction in the food industry. In the case study, for each of the scenarios, SCOR model metrics are ascertained and additional metrics are added such as $\mathrm{CO}_{2}$ emission, energy use, or waste. A "To-Be" scenario is developed for which cost, lead-time, delivery, and $\mathrm{CO}_{2}$ emission impacts are calculated by using the "sustainable supply chain evaluation model". The reference model developed by Wittstruck and Teuteberg [37] is based on a comprehensive literature review on Sustainable Supply Chain Management (SSCM). The overall reference model consists of smaller model components as well as their dependencies. A further "green" reference model was developed as an objective of the "ECO-Integral" project, as described by Dold [13] and Fettke and Loos [16]. It is a cross-industry model for environmental accounting. It consists of one database and instruments of environmental management which use the given database.

The following three models in Table 2 (columns 6-8) are developed or adjusted to be used by some sort of LSP. First is the "IRM model" developed by Gerosa and Taisch [19] as part of a EU-funded project, InCoCo-S. It is a model built for collaboration between service providers and manufactures $[19,38,39]$. Lepori et al. [40] did not develop any new reference model, they made use of a case study for the SCOR model focused on the warehouse of a 3PL. The paper shows the challenges of implementing a blueprint reference model in a practical scenario. Fürstenberg and Tentrop [18] presented the findings of the research project SOA4LOG in their final report. The aim was to develop a generic reference model for international logistic networks in the transportation and service areas. The model is based on four existing reference models and also includes the SCOR model. As actors and users of the model different LSPs are named in it.

The last two models in Table 2 do not fully fit the three search categories, but provide a helpful insight for the RM developement. In the paper of Becker et al. [41], the authors develop a RFID-Reference model focusing on the RFID delivery processes of a manufacturer. A process overview includes the processes from the viewpoint of an LSP or other service providers. Another model focusing on internal processes is the German reference model for handling and picking developed by Scholz [42] as part of the Fraunhofer IML. While it is not specifically 
Lößer L. A Procedure Model for Low Emission Transportation Chain Planning

\begin{tabular}{|c|c|c|c|c|c|c|c|c|}
\hline 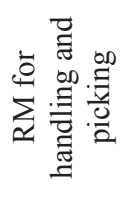 & $\stackrel{\widetilde{I}}{ \pm}$ & 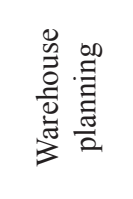 & - & 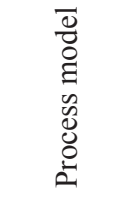 & $\sum_{2}$ & 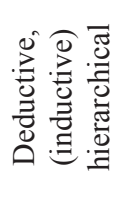 & $\frac{n}{2}$ & 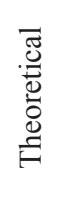 \\
\hline 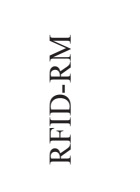 & $\bar{\Xi}$ & 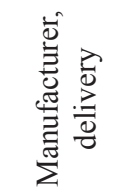 & 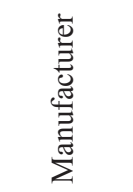 & 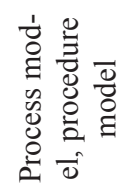 & $\begin{array}{l}0 \\
0 \\
i=1 \\
\sum_{i=1}\end{array}$ & 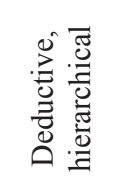 & - & 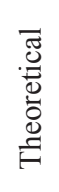 \\
\hline 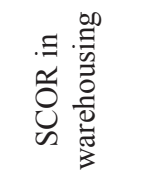 & $\bar{q}$ &  & $\vec{m}$ &  & 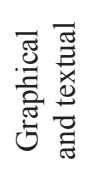 & 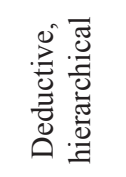 & - & 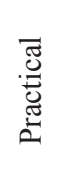 \\
\hline 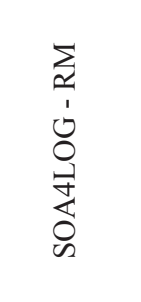 & $\stackrel{\infty}{\Xi}$ & 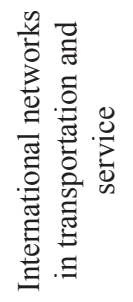 &  & 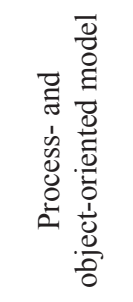 & $\sum_{S}$ & $\begin{array}{l}\stackrel{D}{0} \\
\overline{0} \\
\bar{\Xi} \\
0\end{array}$ & $\begin{array}{l}\stackrel{0}{\overparen{1}} \\
\stackrel{0}{\Sigma}\end{array}$ &  \\
\hline$\sum_{\cong}$ & $\begin{array}{l}\sigma \\
\dot{m} \\
\infty \\
\infty \\
2 \\
2\end{array}$ & 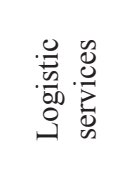 &  & 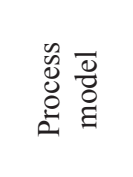 & 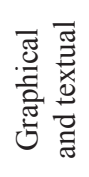 & 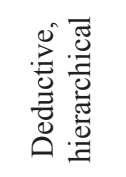 & 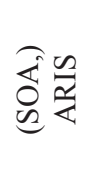 & 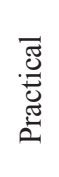 \\
\hline 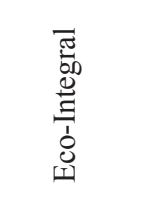 & $\begin{array}{l}\sqrt[\sigma]{\Xi} \\
\stackrel{\Xi}{\Xi}\end{array}$ & 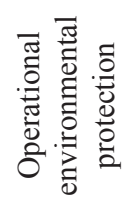 & - & 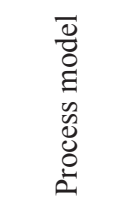 & 足 &  & $\frac{\pi}{2}$ & 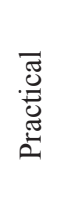 \\
\hline $\begin{array}{l}\sum_{0} \\
W \\
0 \\
\vdots \\
\sum_{n}\end{array}$ & $\underset{\sim}{\approx}$ & $\begin{array}{l}\sum_{0} \\
\text { D } \\
n\end{array}$ & - & 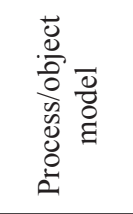 & 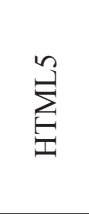 &  & 豆 & 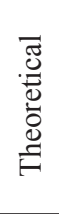 \\
\hline 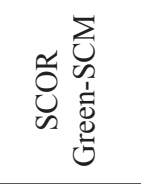 & $\underset{D}{\varnothing}$ & 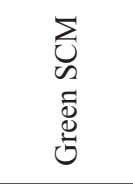 & - & 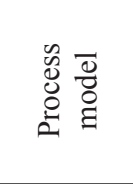 & 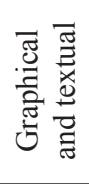 & 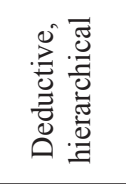 & - & 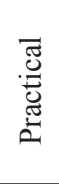 \\
\hline 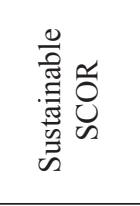 & $\underset{n}{\infty}$ & $\sum_{U=\infty}$ & 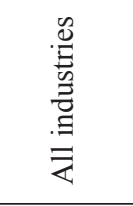 &  & 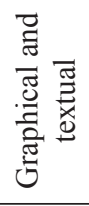 & 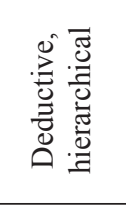 & - & - \\
\hline $\begin{array}{l}\bar{\Xi} \\
\sum_{0}^{0} \\
0 \\
\vdots \\
\\
\end{array}$ & 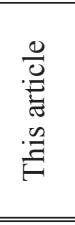 & 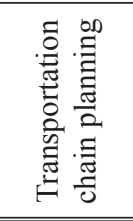 & 荃 & 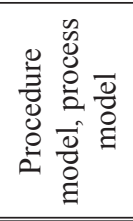 & 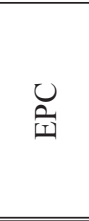 & 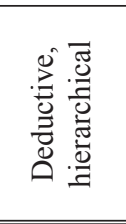 & $\frac{n}{2}$ & 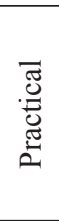 \\
\hline 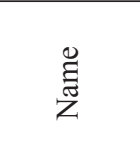 & 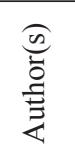 & $\begin{array}{l}\text { :ี } \\
\text { ڤั๊ }\end{array}$ & 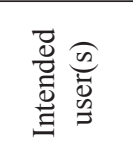 & $\begin{array}{l}\overline{0} \\
\stackrel{0}{0}\end{array}$ &  & 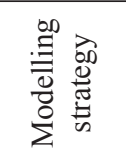 & 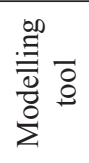 & 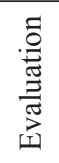 \\
\hline
\end{tabular}


meant for transport or LSP, the reflections and processes included in it are rated as useful insights for the LETC model.

The literature analysis shows that there is no reference model so far that meets all the mentioned requirements such as emission orientation, transportation planning, and the presence of a logistic service provider as user. But some important insights can be drawn from the analysis. Most of the reviewed research studies either implement or extend their reference model to the SCOR Model or base the former on the latter. There are limitations to the use of the SCOR model in the explicit framework of this work. The sustainable SCOR-Model provides the possiblity of emission accounting, it is not meant for low-emission planning approaches. Also, there are no top-level emission KPIs.

Fürstenberg and Tentrop [18] state that the focus of the SCOR Model is on processes connected with physical production, which differs from the processes required for transportation service planning. Lepori et al. [40] show that not all processes in SCOR are needed to solve any problem and, at the same time, not all processes needed are included. All models described offer different kinds and extents of beneficial insights into the reference model developing procedure.

Also, further steps that need to be included in the scope definition phase are identified. As stated before, the identified RMs in Table 2 are also used to make basic modelling decisions. Thus, the yet-to-be discussed categories in Table 2 are focused on. They present the next steps that are needed to be taken in the scope definition phase and include the type of model, modelling language, modelling strategy, modelling method, and modelling tool.

For the development, a procedure model is built but the reference model itself is developed as a process model. The justification for the choice is found by looking into the services of LSP's or 3PLs. The planning of low-emission transportation chains is a complex task because of various interactions of transportation, transhipment and warehousing processes, and activities which are generally triggered by an event. As seen in the definitions of the different kinds of models, this is modelled on processes $[43,44]$.

The next paragraph is concerned with the modelling languages which are used to represent reference models. The SCOR and SCOR-based models use exclusively a graphical and textual model formula- tion; and they need to be translated into a specific model and into a fitting modelling language for the tool of the user. The model thus developed is to be tested in a case study and, therefore, more than a textual and graphical representation is needed. The SOA4LOG - RM is based on the RM for handling and picking. Both use a language developed by the German Fraunhofer Institute. It is named IUM and is an object-oriented modelling approach, not an event-oriented one. The development of a process model triggered by events in a business decision context means a focus on BPML (business process modelling languages). Only once was a BPML used in the literature review and it was for the Eco-Integral model which was formulated as "Event-Driven Process Chain" (EPC) model [13]. Fettke and Loos [16] made an extensive literature review on reference models and concluded that 'for the business process view of reference models, EPC's are used in many cases'. Business process modelling with EPC has often been replaced by the business process modelling notation (BPMN) which is a standard for business process modelling [45]. But no reference model built with BPMN could be found, which could be explained with the statement of Allweyer [45] that 'BPMN is not useful for the development of a meta-model, rather for the use of one'. The extended event-driven process chain (eEPC) is a further development of the EPC [16]. The eEPC is argued to be 'used as a starting point for the development of information systems and for the definition of workflows' by Tsironis et al. [46]. Overall, the EPC or eEPC seem to be fitting languages for the chosen problem as Behdani et al. [47] state: 'At its most basic level, the passage of a consignment through an intermodal freight system is equivalent to a sequence of logistical events. Each event takes the goods from one logistical state to another by performing a logistical activity.'

The next step is the determination of the modelling strategy. Two different strategies for reference models are distinguished by Fettke [48]. The deductive strategy is a top-down approach; generic theories and principles are the starting point for the development of a reference model, which is specified during the development step. The inductive strategy is a bottom-up approach; a specific enterprise model as reference model is developed and in the development procedure the model gets more abstract. For the LETC-RM, the deductive strategy is chosen 
and the model is to be developed as generic model which can later be adjusted to a specific model for the user.

As modelling tool the software ARIS Express is used. ARIS includes different modelling languages such as EPC, eEPC and BPMN. It was developed in 1992 by Prof. Dr. August-Wilhelm Scheer. ARIS includes five views: function, organisation, data, product/service, and control view.[49]. As all modelling decisions on modelling language, strategy and tool have now been made, the next steps for the scope definition are the identification of the main processes and the first level sub-processes of the LETC-RM.

As defined before, a multi-mode planning is to be used in order to reach a modal shift which is one of the main strategies of emission reduction in transportation [10]. The strategy and the reduction are to be achieved by combining the modes: road, rail, and water. The transportation by air is not considered due to high emissions. The planning for multi-mode transportation chains is based on the choice of modes which are to be used. In a vast literature review, only a tiny number of articles and books could be found dealing with the process of mode choice. They are listed in Table 3. One of the reasons could be that it seems to be an easy process to choose modes but, as Reis and Macario [30] state, how these decisions are made in practice is often unknown. As already mentioned in the introduction, most of the decision-makers do not know how the modes are chosen. Bask and Rajahonka [12] and Reis and Macario [30] state that these decisions are often taken at lower levels of authority and are based on known routes and supplier choices.

The earliest model was created in 1977 by Stock et al. [50]. They identified four basic stages for their "Modal Selection Decision Model" by interviewing 357 firms. The stages included: problem recog- nition, search, choice, and post-choice evaluation stage. Each of these stages is divided into sub-processes. The most recent book containing a "mode choice model" was published in 2019 by Reis and Macario [30]. The model itself was developed by D'este and Schneider [51] who called it a 'transportation carrier selection process'. The steps are meant to reduce the transport options, first by including a feasibility test, then a test for meeting service criteria, after that a trade-off between the options that are left is made, and the last step is the choosing of an option. The last model shown in Table 3 is the only one not concerned with intermodal freight transportation planning. The "Theory of Routine Mode Choice Decisions" from Schneider [52] is a model focusing on routine decisions of people. The modes they take, for example, for local shopping - they could either walk or ride a bike, drive a car or take a transit bus.

In comparison, even though the last model [52] has a somewhat different purpose to the other three, the steps that are taken are still very similar to those mentioned in the other models. All four models reach a simplification of the complex planning of transportation chains. In the following, the basic LETC-RM framework (step 3.1 in the procedure model), including the main processes and one level of sub-process, is built on the models that have been introduced.

\section{Reference model framework}

The framework is depicted in Figure 3. The main process (right-hand side) and sub-processes as well as the description of the different steps are deduced from the combination of all four articles or books $[30,50-52]$. The presented framework in Figure 3 is a first generic representation of the LETC model. The databases to be used, important service criteria, and evaluation criteria need to be defined for

Table 3 - Models for Mode Decision Making

\begin{tabular}{|c|c|c|c|}
\hline Author & {$[50]$} & {$[51],[30]$} & {$[52]$} \\
\hline Name & $\begin{array}{l}\text { Modal selection } \\
\text { Decision model }\end{array}$ & $\begin{array}{l}\text { Transportation carrier selection process } \\
\text { Mode choice model }\end{array}$ & $\begin{array}{l}\text { Theory of routine mode choice } \\
\text { decisions }\end{array}$ \\
\hline Main processes & $\begin{array}{l}\text { 1) Recognition stage } \\
\text { 2) Search stage } \\
\text { 3) Choice stage } \\
\text { 4) Post-choice - } \\
\text { evaluation stage }\end{array}$ & $\begin{array}{l}\text { 1) Elimination of technically unfeasible options } \\
\text { 2) Elimination of options that fail to meet service } \\
\text { criteria } \\
\text { 3) Trade-off between service characteristics } \\
\text { 4) Choice }\end{array}$ & $\begin{array}{l}\text { 1) Awareness \& availability } \\
\text { 2) Basic safety \& security } \\
\text { 3) Convenience and cost } \\
\text { 4) Enjoyment } \\
\text { 5) Habit }\end{array}$ \\
\hline Area & $\begin{array}{l}\text { Intermodal freight } \\
\text { transportation }\end{array}$ & Intermodal freight transportation & Public mobility/Transportation \\
\hline
\end{tabular}







any specific user. The generic processes and the appropriate events and activities are described in the following.

Process 1: Awareness \& availability. An incoming order triggers the business process. In order to search for multi-mode alternatives, different types of information need to be gathered from familiar high-performance transport options (companies' database with already successful planned transportation chains), current carrier's sales calls, or additional information which is gathered in databases. A combined database including all transportation chain options for the order is created.

Process 2: Elimination of unfeasible options. The database built for a specific order is used as a basis for checking the feasibility of the options. Some transportations are not actionable with the given transport options. For example, shipping of food proves to be difficult and, therefore, it requires a specific kind of transport [51]. If no feasible option is found first, a second search for new and not-yet-considered options is made. If still no solution is found, the order is refused and the process ends. If at least one feasible option is found, a reduced database is created including only these options.

Process 3: Elimination of options that fail to meet service criteria. The feasible option database is then used to check if the service requirements of the customer, like the maximum cost or transportation time, and the own set of requirements, for example a maximum emission of the transportation chain, can be met. Thus, information about possible carriers for the different modes is needed also. A similar procedure for Process 2 is followed. If no option is left after the check, fresh negotiations with the customer are made to change the service criteria. If this is refused, or even after changing the criteria no option is found, the order is again refused from either side and the process ends. If one or more options are found which meet the service requirements, a further reduced database is created including only these "service options".

Process 4: Choice. Before a choice can be made the options need to be weighed up in order to reach comparability. Afterwards, the choice of one option can be made; and for realisation of the same a specific carrier needs to be chosen as well. The transportation is made.
Process 5: Evaluation. The event of executed transportation triggers the evaluation process. The performance of such transportation needs to be determined for future decisions. Different sources of information can be consulted and the information is stored in a performance database. The evaluation needs to be made based on fixed rules. The performance evaluation calls for a definition of evaluation criteria and calculation of same. As orientation the first level performance attributes of the SCOR-model are used, including Reliability, Responsiveness, Agility, Costs, and Asset Management Efficiency. Extended by the attribute of Low-Emission.

Process 6: Optimisation. If the evaluation is negative, the high-performance options database is checked from the beginning for this particular transport chain. If the option is in the database, an optimisation process is started by looking into the alternatives of the "service options" database. If not, the process ends at this point and the option is not considered further. If the evaluation is positive, the database is also checked for the transportation option. If it is already in the database, the process ends; if not, it is added for future considerations into the "high performance database" and then the process ends.

\section{Expected benefits of the LETC-RM Framework}

The main benefit of the model is the inclusion of emission considerations and figures on different stages of the decision making process. There are several stages where low-emission considerations are included in order to generate a low-emission transportation planning model, starting with the kinds of transportation options that are considered in Phase 1. It is possible to gather information and search for transport options which are environmental friendly. This can be done by preferring train or ship to truck transportation or by considering if carriers offer electrical transportation options and so on. The activity of checking if the service criteria are met is another point. For that matter, not only are the requirements of the customer considered, but also those of the LSP are taken into account in order to include, for example, a maximum level of emission for the transportation options. The final and most decisive step is the choice of the transport option. The exercise of weighing up the options is conducted under this step with the lowest emission getting the highest score and being chosen as the best option. It may not be the option with the lowest cost, but in the process "elimination of options that 
fail to meet service criteria', it is already ensured that the costs of all options that can be chosen in the end match the service requirements of the customer.

Further benefits are seen in the standardised decision-making process of the model which also leads to a transparent process and emission calculation.

\section{CONCLUSION}

The usability of natural resources is limited and companies need to start working within these limitations, especially considering the most important objective of a company: long-term survival. The problem of increasing emission in transportation is countered with a strategic solution approach in this paper. The main aim of this article is the development of a procedure model which can be used to develop a low-emission transportation chain reference model. The research in this article is limited by the chosen databases and research phrases for the literature reviews. Following the steps in the procedure model a first draft of a reference model framework is developed to show the main decision procedure for logistics service providers using this model. The further steps after the reference model framework represent the further need for research to finalise the model. The developed framework needs to be extended by including a level of activities (additional sub-steps). Key performance indicators including emission figures need to be defined for the process of weighting the service criteria for the choice process and the process of evaluation. The LETC-RM model needs to be tested in a case study and its performance should be evaluated to optimise and finalise the LETC-RM.

\section{LARISSA LÖßER, M.Sc.}

E-mail: larissa.loesser@hs-merseburg.de

Hochschule Merseburg

Eberhard-Leibnitz-Straße 2, 06217 Merseburg, Deutschland

\section{EIN VORGEHENSMODELL FÜR DIE PLANUNG EMISSIONSARMER TRANSPORTKETTEN}

\section{ABSTRAKT}

Emissionsarme Planung im Sektor des Frachtverkehres ist einer der Haupthebel zur Reduktion von Treibhausgasemissionen. Um einen nachhaltigen Planungsansatz $z u$ verfolgen, wird eine strategische Lösung der Planungsprobleme im Frachttransport benötigt. In dieser Arbeit wird, basierend auf mehreren Literaturanalysen, ein Vorgehensmodell entwickelt, für die Entwicklung und Optimierung eines Referenzmodells für emissionsarme Transportkettenplanung. Das Vorgehensmodell bildet die Haupt- und Unterplanungsschritte ab, die für die Entwicklung des "Low Emission Transportation Chain (LETC) Referenzmodells, benötigt warden. Ein erster Entwurf des LETC-Referenzmodells, in Form eines ARIS-Express Modells wird präsentiert und beschrieben.

\section{SCHLÜSSELWÖRTER}

Emissionsarm, Frachttransport, Vorgehensmodell, Referenzmodell.

\section{REFERENCES}

[1] Kendall HW. World scientists' warning to humanity. In: Kendall HW. (ed.) A distant light: Masters of modern physics. New York: Springer; 2000. p. 198-201.

[2] Ripple WJ, et al. World scientists' warning to humanity: A second notice. BioScience. 2017;67: 1026-8. DOI: 10.1093/biosci/bix125

[3] Ripple WJ, et al. Corrigendum: World scientists' warning of a climate emergency. BioScience. 2020;70: 100. DOI: 10.1093/biosci/biz152

[4] UNFCCC. Nationally determined contributions (NDCs): The Paris Agreement and NDCs. Available from: https:// unfccc.int/process-and-meetings/the-paris-agreement/ the-paris-agreement/nationally-determined-contributions-ndcs [Accessed 10th July 2020].

[5] CAT. Governments still showing little sign of acting on climate crisis: Warming projections global update. 10.12.2019. Available from: https://climateactiontracker.org/publications/governments-still-not-acting-on-climate-crisis/ [Accessed 28th June 2021].

[6] Stubbs W, Higgins C, Milne M. Why do companies not produce sustainability reports? Business Strategy and the Environment. 2013;22: 456-70. DOI: 10.1002/bse.1756

[7] Massaroni E, Cozzolino A, Wankowicz E. Sustainability reporting of logistics service providers in Europe. International Journal of Environment and Health. 2016;8: 38-58. DOI: 10.1504/IJENVH.2016.077662

[8] Rüegg-Stürm J. [The new St. Galler Management Model] In: Rüegg-Stürm J, Euler D, Dubs R, Wyss CE. (eds.) [Introduction into Management]. Stuttgart, Germany: Haupt; 2004, p. 65-140. German.

[9] Rieder L, Lawson R. Management control with integrated planning: Models and implementation for sustainable coordination. Stuttgart, Germany: Springer; 2020.

[10] UBA. [Climate protection aims of Germany: Greenhouse gas emissions covered by the UN Climate Convention]. Available from: https://www.umweltbundesamt.de/daten/klima/klimaschutzziele-deutschlands [Accessed 17th June 2021]. German.

[11] EC. Transport in the European Union: Current trends and issues. 2019. Available from: https://ec.europa.eu/transport/sites/transport/files/2019-transport-in-the-eu-currenttrends-and-issues.pdf [Accessed 18th June 2021].

[12] Bask A, Rajahonka M. The role of environmental sustainability in the freight transport mode choice. International Journal of Physical Distribution \& Logistics 
Management. 2017;47: 560-602. DOI: 10.1108/IJPDLM-03-2017-0127

[13] Dold G. [Efficient environmental Management with ECO-Integral]. In: Freimann J. (ed.) [Tools of successful environmental management: A compendium for the praxis]. Wiesbaden, Germany: Springer-Verlag; 1999. p. 71-94. German.

[14] Becker J, Delfmann P, Knackstedt R, Kuropka D. [Configurative reference modelling]. In: Becker J, Knackstedt R. (eds.) [Knowledge management with reference models: Concepts for the application system and organisation configuration]. Heidelberg, Germany: Physica-Verlag HD; 2002. p. 25-140. German.

[15] Fettke P, Loos P. [The reference model catalogue as tool for knowledge management: Methodology and application]. In: Becker J, Knackstedt R. (eds.) [Knowledge management with reference models: Concepts for the application system and organisation configuration]. Heidelberg, Germany: Physica-Verlag HD; 2002. p. 3-24. German.

[16] Fettke P, Loos P. Business process reference models: Survey and classification. In: Bussler C, et al. (eds.) International Conference on Business Process Management, 5 Sep. 2005, Nancy, France. Berlin, Germany: Springer; 2005. p. 469-483.

[17] Thomas O. Understanding the term reference model in information systems research: History, literature analysis and explanation. In: Bussler C, et al. (eds.) International Conference on Business Process Management, 5 Sep. 2005, Nancy, France. Berlin, Germany: Springer; 2005. p. 484-496.

[18] Fürstenberg F, Tentrop F. [Development of a practice reference model for international logistic networks]. Berlin, Germany: Univerlag TU Berlin; 2008. German.

[19] Gerosa M, Taisch M. A logistic service provider reference model. IFAC Proceedings Volumes. 2009;42: 1340 5. DOI: 10.3182/20090603-3-RU-2001.0444

[20] Matook S, Indulska M. Improving the quality of process reference models: A quality function deployment-based approach. Decision Support Systems. 2009;47: 60-71. DOI: 10.1016/j.dss.2008.12.006

[21] Schütte R. [Reference modelling: Requirements in praxis and methodical concepts]. In: Scheruhn H-J, Maicher M. (eds.) [Information modelling: Reference models and tools]. Wiesbaden, Germany: Springer-Verlag; 2013. p. 63-84. German.

[22] Schlagheck B. [Object-oriented reference models for the process and project controlling: Basics - construction - possible applications]. Wiesbaden, Germany: Gabler, 2000. German.

[23] Hars A. [Reference models: Basics of efficient data modelling]. Wiesbaden, Germany: Springer-Verlag; 1994. German.

[24] Fettke P, Loos P. [The contribution of reference modelling to business engineering] HMD-Praxis der Wirtschaftsinformatik. 2005;241: 18-26. Available from: https://www.econbiz.de/archiv/mz/umz/winformatik/ beitrag referenzmodellierung.pdf [Accessed 29th June 2021]. German.

[25] Tzouvaras A, Hess T. [Reference modelling for book publishers: First reflections from a structure-orient- ed point of view]. In: Becker J, Knackstedt R. (eds.) [Knowledge management with reference models: Concepts for the application system and organisation configuration]. Heidelberg, Germany: Physica-Verlag HD; 2002. p. 177-194. German.

[26] Becker J, Rosemann M, Schütte R. [Principle of proper modelling]. Wirtschaftsinformatik. 1995;37: 435-45. Available from: https://www.researchgate.net/profile/ Michael-Rosemann/publication/220596134_Grundsatze_ordnungsmassiger_Modellierung/links/

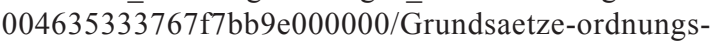
maessiger-Modellierung.pdf [Accessed 11th June 2021]. German.

[27] Schedlbauer MJ. [Adaptive logistical planning based on a standardized, process-oriented building block concept]. PhD. Thesis. Technische Universität Munich; 2008. German.

[28] Lößer L, Sackmann D. Problems and challenges for measuring and reducing emissions of intermodal transportation chains. In: Zanne M, Bajec P, Twrdy E. (eds.) $19^{\text {th }}$ International Conference on Transport Science (ITCS), 17-18 Sep. 2020, Portoroz, Slovenia. Faculty of Maritime Studies and Transport; 2020. p.177-184.

[29] Lößer L. Characteristics and environmental orientation of modality concepts. In: Logistics Management 2021 Conference Proceedings; 2021.

[30] Reis V, Macario R. Intermodal freight transportation. Elsevier; 2019.

[31] Bask A, et al. Environmental sustainability in shipper-LSP relationships. Journal of Cleaner Production. 2018;172: 2986-98. DOI: 10.1016/j.jclepro.2017.11.112

[32] Lun YV, et al. Greening propensity and performance implications for logistics service providers. Transportation Research Part E: Logistics and Transportation Review. 2015;74: 50-62. DOI: 10.1016/j.tre.2014.10.002

[33] Vasiliauskas AV, Jakubauskas G. Principle and benefits of third-party logistics approach when managing logistics supply chain. Transport. 2007;22: 68-72. DOI: 10.1080/16484142.2007.9638101

[34] Rixe C, Augustin H. [Reference models for intralogistics: Courses of action for the construction of an intralogistics reference model]. ZWF. 2020;115: 894-8. DOI: $10.3139 / 104.112436$

[35] SSC. SCOR: Supply Chain Reference Model: Version 12.0. 2017. Available from: http://www.logsuper.com/ ueditor/php/upload/file/20190530/1559181653829933. pdf [Accessed 26th June 2021].

[36] Ala-Harja H, Helo P. Reprint of "Green supply chain decisions - Case-based performance analysis from the food industry". Transportation Research Part E: Logistics and Transportation Review. 2015;74: 97-107. DOI: 10.1016/j.tre.2014.12.005

[37] Wittstruck D, Teuteberg F. [A reference model for sustainable supply chain management]. Zeitschrift für Management. 2010;5: 141-64. DOI: 10.1007/s12354-0100122-0

[38] Osadsky $\mathrm{P}$, et al. Improving service operation performance by a cross-industry reference model. In: Olhager J, Persson F. (eds.) IFIP International Federation for Information Processing. Boston, US: Springer; 2007. p. 397-404. 
[39] Heinzel H, Garg A, Schleyer S. Integrating industrial services into manufacturing supply chains. 2007. Available from: https://www.bptrends.com/integrating-industrial-services-into-manufacturing-supply-chains/ [Accessed 12th June 2020].

[40] Lepori E, Damand D, Barth B. Benefits and limitations of the SCOR model in warehousing. IFAC Proceedings Volumes. 2013;49(9): 424-429. DOI: 10.3182/20130619-3RU-3018.00174

[41] Becker J, Vilkov L, Weiß B, Winkelmann A. A model based approach for calculating the process driven business value of RFID investments. International Journal of Production Economics. 2010;127: 358-71. DOI: 10.1016/j.ijpe.2009.08.025

[42] Scholz I. [Reference model for handling and picking]. In: Wenzel S. (ed.) [Reference models for simulation in production and logistics]. Ghent, Belgium: SCS Europe; 2000. p. 211-231.

[43] Chen C-C.A model for customer-focused objective-based performance evaluation of logistics service providers. Asia Pacific Journal of Marketing and Logistics. 2008;20: 309-22. DOI: 10.1108/13555850810890075

[44] Carbone V, Stone MA. Growth and relational strategies used by the European logistics service providers: Rationale and outcomes. Transportation Research Part E: Logistics and Transportation Review. 2005;41: 495-510. DOI: $10.1016 /$ j.tre.2005.06.001

[45] Allweyer T. BPMN 2.0 - Business Process Model and Notation: [Introduction for the standard of business process modelling]. 4th ed. Norderstedt: BoD-Books on De- mand; 2020. German.

[46] Tsironis L, Anastasiou K, Moustakis V. A framework for BPML assessment and improvement: A case study using IDEF0 and eEPC. Business Process Management Journal. 2009;15: 430-61. DOI: 10.1108/ 14637150910960657

[47] Behdani B, Fan Y, Wiegmans B, Zuidwijk R. Multimodal schedule design for synchromodal freight transport systems. EJTIR. 2014;16(3): 424-44. DOI:10.2139/ ssrn. 2438851

[48] Fettke P. [A method for an inductive development of reference models]. In: Kundis D, Suhl L, Beckann L. (eds.) MKWI 2014 - Multikonferenz Wirtschaftsinformatik, 26-28 Feb. 2014, Paderborn, Germany. Paderborn, Germany: Gito-Verlag; 2014. p. 1034-1047. German.

[49] Scheer A-W. [Business information systems: Reference models for industrial business processes $]$ 6 $^{\text {th }}$ ed. Berlin, Germany: Springer-Verlag; 1998. German.

[50] Stock JR, La Londe BJ. The transportation mode decision revisited. Transportation Journal. 1977;17: 51-9. DOI:10.1016/j.tranpol.2012.10.007

[51] D'Este G, Schneider RJ. An event-based approach to modelling intermodal freight systems. International Journal of Physical Distribution \& Logistics Management. 1996;26(6): 4-15. DOI: 10.1108/09600039610145899

[52] Schneider RJ. Theory of routine mode choice decisions: An operational framework to increase sustainable transportation. Transport Policy. 2013;25: 128-37. DOI: 10.1016/j.tranpol.2012.10.007 